\title{
LA AUTORIZACION JUDICIAL: GARANTIA DE LA INVIOLABILIDAD DE DOMICILIO Y LIMITE DE LA, EJECUCION FORZOSA DE LOS ACTOS ADMINISTRATIVOS
}

340.142: 342.722

por

\section{Tomás Quintana López}

Con la sentencia número 22/1984, de 17 de febrero ( $B O E$ de 9 de marzo de 1984), dictada en el recurso de amparo número 59/1983, por la Sala Segunda del Tribunal Constitucional, se da un paso más en la interpretación de nuestra Norma Fundamental; en esta ocasión le ha correspondido al artículo 18, concretamente, ha sido objeto de estudio y delimitación una faceta del derecho a la inviolabilidad de domicilio (1), derecho enmarcado dentro del más amplio derecho a la intimidad (2).

La cuestión que se plantea a nuestro Alto Tribunal no es nueva, si bien la solución a que se llega en estos momentos sí lo es, comparándola con supuestos similares suscitados ante otras instancias jurisdiccionales. Los hechos y el iter procesal del asunto, detallados en los antecedentes de la sentencia, ponen de manifiesto el conflicto entre la facultad de ejecución de sus propios actos que la Administración pública ostenta, y que nadie discute, y el necesario respeto

(1) Sobre el tema, puede verse en $R E D A, 32$, págs. 855 y sigs., Ricardo GaRctA MACHO: "La inviolabilidad de domicilio».

(2) A. García Vitoria: El derecho a la intimidad en el Derecho penal y en la Constitución de 1978, Editorial Aranzadi, Pamplona, 1983. También, Luis M. Farinas MATONI: El derecho a la intimidad, Madrid, 1983. 
a los derechos fundamentales. En el caso comentado, la inviolabilidad de domicilio puede verse afectada al llevar la Administración al terreno de los hechos lo previamente declarado por ella.

Como antes se indicaba, no es la primera vez que se presenta un asunto semejante ante nuestros Tribunales (3), si bien la solución, condicionada, sin duda, por circunstancias jurídico-positivas y políticas diversas a las actuales, no ha sido la misma que la mantenida en esta ocasión por la Sala Segunda del Tribunal Constitucional. Ya en el año 1977 era objeto de atención una sentencia de la Audiencia Territorial de Burgos (de fecha 23 de octubre de 1975), que al resolver en un caso análogo al ahora tenido en cuenta, suscitaba la siguiente reflexión del comentarista (4):

«...Un principio que no tolera excepciones en el marco de un Estado de Derecho de carácter democrático es el respeto de las libertades públicas... Por ello, cuando, como en este supuesto, se genera una tensión entre privilegio de ejecutoriedad y derechos fundamentales debe instrumentarse la intervención - todo lo sumaria y ágil que se estime conveniente, pero obligada- del Juez».

No se podía hacer más en aquel momento, en que pese a reconocerse el derecho a la inviolabilidad del domicilio, el Fuero de los Españoles ponía en manos de la autoridad competente la posibilidad de expedir mandamientos para entrar en el domicilio ajeno contra la voluntad de su titular. Teniendo en cuenta que autoridad competente no tenía por qué equivaler a autoridad judicial, no parece violentar las normas resolver como entonces lo hizo la Audiencia Territorial de Burgos. En esas circunstancias, no quedaba más que abogar por la extensión a otros órdenes normativos de la solución dada por el artículo 130 de la Ley General Tributaria, según la cual se precisa la autorización judicial para que el Recaudador entre legítimamente en el domicilio de los deudores responsables providenciados de apremio.

La aprobación de la Constitución impone, en éste como en otros tantos temas, una solución distinta. La literalidad del artículo 18 de la Constitución, el carácter que tiene de norma de efecto inmediato, conduce a una revisión de la doctrina preconstitucional.

(3) Con ciertas similitudes, pese a no llegar a plantearse el problema aquí suscitado, cabe tener en cuenta la sentencia «Capuchinos de Sarriá», comentada por Tomás Ramón FernÁNDEZ, en RAP, 61, págs. 125 y sigs.

(4) F. SOSA WAGNER: «Ejecución forzosa e inviolabilidad de domicilio», en $R E D A, 14$, págs. 481 y sigs. 
Sin desvirtuar la potestad administrativa de autotutela, que la sentencia admite sin mayores problemas, a continuación señala:

«...La Administración, que a través de sus órganos competentes procede a la ejecución forzosa de actos administrativos, tiene que respetar los derechos fundamentales de los sujetos pasivos de la ejecución».

Admitida esta conclusión, obtenida incluso a partir del artículo 108 de la Ley de Procedimiento Administrativo, delimita el conflicto a resolver en los términos que siguen:

«De esta manera el objeto central de nuestro asunto se reduce a constatar si cuando la ejecución forzosa realizada en un procedimiento administrativo por la Administración, en virtud de la llamada autotutela de ejecutar sus decisiones, requiere la entrada o el registro en el domicilio de una persona, para llevarlo a cabo basta el título que ordena la ejecución o es preciso dar cumplimiento a los requisitos del artículo 18 de la Constitución».

Lo que subyace en el anterior texto transcrito es la tensión entre un fin social, que exige la demolición de un inmueble que sirve de domicilio a un sujeto, $y$ el respeto a los derechos fundamentales inherentes al libre desarrollo de la personalidad, elevados por la Constitución a la categoría de fundamento del orden político y de la paz social. El equilibrio entre estos dos polos, que si no opuestos, pueden entrar en colisión, es alcanzado en esta ejemplar sentencia con un escrupuloso respeto a la inviolabilidad de domicilio. El tenor de la resolución es la mejor muestra de lo que acabamos de decir. Ante lo aducido por el Fiscal general en los siguientes términos: "El ejercicio de un derecho fundamental no puede alegarse para entorpecer un fin social, que, como general, es de rango superior», la Sala Segunda del Tribunal Constitucional señala:

«...Una afirmación como la anterior, realizada sin ningún tipo de matizaciones, conduce ineludiblemente al entero sacrificio de todos los derechos fundamentales de la persona y de todas las libertades públicas a los fines sociales, lo que es inconciliable con los valores superiores del ordenamiento jurídico que nuestra Constitución proclama. Existen, ciertamente, fines sociales que deben considerarse de rango superior a algunos derechos individuales, pero ha de tratarse de fines sociales que constituyan en sí mismos valores constitucionalmente reconocidos y la prioridad ha de resultar de la propia Constitución». 
La armonía entre estos dos polos de fricción ya tiene su cómodo asiento en esta doctrina. La prioridad indiscriminada de los fines sociales, aun a costa de los más elementales derechos fundamentales, conduce, inevitablemente, a una visión del individuo como súbdito, en vez de ciudadano, condición que intencionadamente ha marginado nuestro constituyente de la Norma Fundamental. Precisamente, hay que buscar en esta Norma, y debido a su insuperable grado de legitimación, los fines sociales, los supuestos concretos que elevan su importancia, incluso por encima de los derechos fundamentales y libertades públicas.

Volviendo al tema que se plantea en la alta instancia jurisdiccional, se hace preciso delimitar el alcance de las garantías al servicio del derecho a la inviolabilidad de domicilio, reconocido en el artículo 18, 2, del texto constitucional. Fuera de los supuestos de consentimiento del titular del mismo, o bien en caso de flagrante delito; nadie puede entrar en domicilio ajeno, salvo que haya habido resolución judicial autorizatoria de la entrada. En este punto es precisamente donde surge el problema que se somete a la consideración del Tribunal: es decir, si la Administración, pese a la potestad de autotutela, aun gozando de la facultad de ejecutar sus propios actos sin tener que impetrar el auxilio judicial, ha de proveerse de la correspondiente autorización judicial para llevar a.la práctica sus decisiones previas, cuando éstas impliquen o necesiten la entrada en domicilio ajeno.

La solución en la línea de la doctrina anterior, impuesta por la misma existencia de un Estado democrático de Derecho, no puede ser otra que el llamamiento al Juez para que éste, si lo considera imprescindible, autorice la entrada en el domicilio con el fin de que la Administración, cualquier Administración pública, ejecute en sus propios términos la decisión previamente adoptada. El Juez se erige en garante del respeto a la inviolabilidad del domicilio, acabando con ese tan frecuentemente esgrimido prejuicio, derivado del artículo 546 de la Ley de Enjuiciamiento Criminal, que parece tenía como cierto que sólo se podía vulnerar la intimidad domiciliaria cuando la Administración, a través de sus funcionarios, trata de descubrir o comprobar un delito. Pero la sentencia no agota sus conclusiones en lo antedicho, sino que ahonda aún más, sacando a la luz otra consecuencia de enorme importancia. Porque a los efectos de la garantía y respeto del derecho a la inviolabilidad de 
domicilio, la necesidad de la autorización judicial para entrar sin consentimiento del titular, como textualmente dice la sentencia:

«...No es aplicable únicamente a los casos en que se trata de una resolución tomada por la Administración en virtud de un principio de autotutela administrativa, como ocurre en el presente caso. A la misma conclusión se puede llegar cuando la decisión que se ejecuta es una resolución de la jurisdicción ordinaria en matera civil. Si los agentes judiciales encargados de llevar, por ejemplo, a cabo un desahucio o un embargo encuentran cerrada la puerta o el acceso a un domicilio, sólo en virtud de una específica resolución judicial pueden entrar. Por consiguiente, el hecho de encontrarse ejecutando una decisión judicial o administrativa legalmente adoptada, no permite la entrada y el registro en un domicilio particular. Sin consentimiento del titular o resolución judicial, el acto es ilícito y constituye violación del derecho, salvo el caso de flagrante y salvo, naturalmente, las hipótesis que generan causas de justificación, como puede ocurrir con el estado de necesidad».

De lo que se trata no es de juzgar la actuación administrativa, que quizá ya no admita juicio, pensemos en actos administrativos ya firmes, ni tampoco se pretende volver a juzgar una resolución judicial ya dictada, antes bien, la doctrina de esta sentencia impone someter al criterio del Juez la necesidad de socavar la intimidad domiciliaria para ejecutar un acto administrativo o una decisión judicial previa, sin implicar esta actuación un juicio de la legalidad del acto o resolución, que, si cabe, tendrá su expresión a través de las vías procesales correspondientes. 
REVL-1984, núm. 224. QUINTANA LOPEZ, TOMAS. LA AUTORIZACION JUDICIAL: GARANTIA D... REVL-1984, núm. 224. QUINTANA LOPEZ, TOMAS. LA AUTORIZACION JUDICIAL: GARANTIA D... 